\title{
Fundamentos histórico-sociológicos da acumulação originária no Vale do Itajaí-SC
}

\author{
Cleiton Junior Pereira da Rocha \\ Departamento de Psicologia da Universidade Regional de Blumenau (Furb)
}

Recebido: 18/06/2014 Versão revisada (entregue): 23/09/2014 Aprovado: 30/09/2014

\begin{abstract}
Resumo
O artigo discute os fundamentos da acumulação originária no Vale do Itajaí a partir da metodologia de análise institucional proposta por Karl Polanyi para o estudo da economia de mercado, e seus efeitos sobre os meios locais de subsistência, apropriação produtiva e desenvolvimento estatal do século XIX em diante. Efetua-se uma revisão das proposições de Florestan Fernandes, Caio Prado Junior e Oliveira Vianna, em paralelo à obra de Klaus Richter e Maria Luiza Renaux Hering, para determinar como os conflitos inerentes à constituição econômica do Estado brasileiro podem ser identificados no contexto do Vale do Itajaí desde a fundação da Colônia Blumenau. Apresenta-se visão crítica sobre os determinantes da integração da região do Vale do Itajaí na economia brasileira relacionados à expansão da economia mundial característica do século XIX e início do XX. Demonstra-se como as relações comerciais e políticas do período voltavam-se à construção de instituições públicas aptas à realização de transações que alimentavam o processo de dependência da economia local a investimentos externos e recursos públicos federais. Destaca-se a dupla articulação dependente sustentada a partir da exploração sistemática da força de trabalho dos migrantes nacionais e estrangeiros que formaram a população brasileira da região.
\end{abstract}

Palavras-chave | Brasil; colonização; Karl Polanyi; mercado; política; Vale do Itajaí.

Código JEL | N96; O18; R13.

\section{HISTORICAL-SOCIOLOGICAL FOUNDATIONS OF THE ARISING ACCUMULATION IN THE ITAJAÍ VALLEY-SC}

\begin{abstract}
The article discusses the fundamentals of primitive accumulation in the Itajai Valley by using the methodology of institutional analysis, proposed by Karl Polanyi, for the study of the market economy and for its effects on the local livelihoods, the productive appropriation and the state development since the nineteenth century. It is reviewing the propositions of Florestan Fernandes, Caio Prado Junior and Oliveira Vianna, in parallel to the work of Klaus Richter and Maria Luiza Renaux Hering, to determine how the conflicts related to the economic constitution of the Brazilian state can be identified in the context of the Itajai Valley since the founding of the Blumenau Colony. A critical vision on the determinants of the integration of the regional economy of the Itajai Valley into the Brazilian economy, determinants related to the
\end{abstract}


expansion of the nineteenth and the early twentieth century world economy, is presented. It is demonstrated how the commercial and political relations of the period were oriented to the building of public institutions to provide conditions for the transactions that fed the dependence of the local economy to foreign investments and federal resources. The double dependent articulation, sustained on the systematic exploitation of the workforce of national and foreigner migrant which constituted the Brazilian population in the region, is highlighted.

Keywords | Brazil; colonization; Itajaí Valley; Karl Polanyi; market; policy.

JEL-Code | N96; O18; R13.

\section{FUNDAMENTOS HISTÓRICOS Y SOCIOLÓGICOS DE LA ACUMULACIÓN ORIGINARIA EN EL VALLE DE ITAJAÍ-SC}

\section{Resumen}

El documento analiza los fundamentos de la acumulación primitiva en el Valle del Itajaí utilizando la metodología de análisis institucional propuesta por Karl Polanyi para el estudio de la economía de mercado y sus efectos sobre los medios de vida locales, la apropiación productiva y el desarrollo del estado a partir del siglo XIX. Es realizada una revisión de las proposiciones de Florestan Fernandes, Caio Prado Júnior y Oliveira Vianna en paralelo al trabajo de Klaus Richter y Maria Luiza Renaux-Hering para determinar cómo los conflictos inherentes a la constitución económica del Estado brasileño pueden ser identificados en el contexto del Valle del Itajaí desde la fundación de la Colonia de Blumenau. Es presentada una perspectiva crítica sobre los determinantes de la integración de la región del Valle del Itajaí en la economía brasileña relacionados a la expansión de la economía mundial característica del siglo XIX e inicio del XX. Es demostrado cómo las relaciones comerciales y políticas del período tenían como objetivo la construcción de instituciones públicas capaces de realizar transacciones que alimentaban la dependencia de la economía local de inversiones externas y de recursos públicos federales. Se da destaque a la doble articulación dependiente sustentada a partir de la explotación sistemática de la fuerza de trabajo de los inmigrantes nacionales y extranjeros que formaron la población brasileña de la región.

Palabras-clave | Brasil; colonización; Karl Polanyi; mercado; política; Valle del Itajaí.

Código JEL | N96; O18; R13.

\section{Introdução}

O objetivo da presente investigação está dado pela busca dos determinantes relativos ao processo de instituição dos meios de apropriação voltados ao mercado desenvolvidos no Vale do Itajaí desde o início do século XIX até o processo de diferenciação econômica e financeirização do início do século XX. O sentido comercial da colonização brasileira (PRADO JUNIOR, 1961, 1986; FERNANDES, 1972, 1976), que possibilitou a formação de instituições econômicas voltadas ao mercado exterior, será nosso fio condutor na busca das relações de agenciamento entre os grupos políticos e econômicos que atuaram 
para a institucionalização dos meios de acumulação originários do capitalismo no Vale do Itajaí.

Este artigo apresenta algumas proposições metodológicas e teóricas da análise institucional da economia do Vale do Itajaí realizadas na dissertação de mestrado do presente pesquisador junto ao Programa de Pós-graduação em Sociologia Política da Universidade Federal de Santa Catarina, no ano de 2013. A análise institucional dos mercados proposta por Karl Polanyi $(1957,2000)$ é retomada como meio para o questionamento das premissas que definem o processo de acumulação originária e formação de economia mercantil (MARX, 1989, 1991, 2007, 2010, 2011) de capital no Vale do Itajaí, entre meados do século XIX e início do XX.

As fontes são predominantemente bibliográficas, partindo de apropriação crítica de algumas obras relevantes em torno do tema da formação econômica e política do Brasil em contraste com o desenvolvimento da cidade de Blumenau, desde sua origem colonial no século XIX, com relevância central para a obra de Klaus Richter (1992, 2004, 2006, 2007). Pretendemos deslocar o debate da construção econômica local de uma suposta base institucional autônoma, explicada por recursos culturais próprios, para uma visão integradora que possui nos processos instituídos de produção e gestão local sua visibilidade mais abrangente.

\section{Acumulação originária, mercado e liberalismo}

Ao realizar sua crítica da economia política, Marx denunciou a utilização da economia como meio para a legitimação da ordem institucional do mercado. Dentre suas preocupações centrais estava a desnaturalização dos conceitos clássicos utilizados pela economia de raiz liberal, expondo sua relação direta com a expropriação dos trabalhadores urbanos e camponeses que se desenvolvia na Europa no mesmo período do século XIX. O ordenamento econômico liberal emergiria como instrumento ideológico de dominação de classe, visando à construção de um arcabouço jurídico e político dirigido pelos proprietários europeus como meio para legitimar socialmente os novos arranjos produtivos decorrentes da transformação das relações de produção em curso durante a Revolução Burguesa (MARX, 1989, p. 829).

Esse processo de acumulação originária ou primitiva caracterizou-se historicamente pelo rompimento com as instituições feudais na Europa em favor do modelo de mercado. Estas atividades comerciais seriam responsáveis por iniciar a colonização e o povoamento das Américas, tomando por referência, para a constituição econômica das colônias, os mesmos arranjos institucionais do mercado e do Estado Nacional em construção na Europa. 
Ao tomar o progresso do mercado como base para a organização civilizatória, as concepções modernas da economia compreendem a evolução histórica como determinada pelo avanço destas instituições. O progresso faria com que qualquer dificuldade presente fosse considerada apenas como um passo a mais a ser dado em direção ao futuro, e a lentidão dessa caminhada nas terras coloniais encontraria uma variada gama de explicações singularizadas por cada campo de pesquisa da ciência moderna. "Já não são unicamente o capital e o trabalho per se que estão em jogo, mas a reprodução do código. A realidade transforma-se, para tomar emprestada a expressão de Baudrillard, no espelho da produção." (ESCOBAR apud LANDER, 2005, p. 18).

A questão torna-se mais complexa ao admitirmos que as categorias econômicas liberais agiram de forma substantiva na composição das instituições de intercâmbio e administração coloniais do Brasil do século XIX (FERNANDES, 1959, 1972, 1976). A consolidação da moderna teoria liberal foi acompanhada da real liberalização da economia em nível mundial, fato este que impõe à análise da formação social colonial a constante tensão entre as normativas de uma economia em implementação - que teria o predomínio sobre as instituições jurídicas e políticas em formação - e o modo singular de organização produtiva de cada centro colonial e suas características próprias de ocupação, que só podem ser analisadas historicamente. Nesse contexto de mediação entre o capital e as instituições modernas, o desenvolvimento das formas estatais adquire relevância fundamental para a compreensão do desenvolvimento dos modos de apropriação dos recursos coloniais.

Segundo Polanyi, Arensberg e Pearson (1957), a economia empírica pode ser definida como o processo instituído de interação entre o homem e seu ambiente, que resulta em contínua produção de meios para satisfação de necessidades materiais ${ }^{1}$. Na análise da economia de mercado, a organização dos meios produtivos institui dois processos: os movimentos localizados de organização da produção e subsistência e os de apropriação, constituintes de riqueza social através da exploração dos recursos do território. Os movimentos localizados incluem a organização da produção e do transporte; já a apropriação refere-se ao que usualmente define-se como circulação e administração de bens, alterando sua condição social - transformação dos meios de produção em mercadorias. O primeiro caso refere-se a transações, o segundo, a disposições.

No contexto do século XIX, segundo Polanyi, Arensberg e Pearson (1957), é possível observar que corporações privadas estavam associadas às transações

\footnotetext{
1 The fount of the substantive concept is the empirical economy. It can briefly (if not engagingly) defined as an instituted process of interaction between man and his environment, which results in a continuous supply of want satisfying material means (POLANYI; ARENSBERG; PEARSON, 1957, p. 248).
} 
enquanto os agentes públicos estavam usualmente creditados com as disposições². No caso da economia de Blumenau, observamos que as disposições para o estabelecimento colonial foram conduzidas pelo governo do Império - e posteriormente pela República -, enquanto as empresas comerciais e as companhias de capital estrangeiro figuram como agentes das transações que instituiriam os movimentos de apropriação.

Particularmente em relação ao século XIX, com o crescimento expressivo das redes de comércio exterior, a ênfase na "aquisição de bens de origem distante" fizeram com que os interesses exportadores crescessem acentuadamente ${ }^{3}$. Para compreender as possibilidades institucionais de desenvolvimento colonial naquele período, é necessário, portanto, verificar o vínculo de cada nicho econômico colonial com o mercado exterior que o inscreve de forma mais marcante no seio do mercado mundial.

Os movimentos localizados de constituição de disposições determinavam o que poderia ser produzido e quais recursos externos seriam buscados. A construção e a manutenção de uma colônia dependiam de condições internas instituídas de forma localizada. No caso de Blumenau, a principal delas foi a produção de alimentos para subsistência, que encetou uma cadeia produtiva local cujo objetivo era a estabilidade e viabilidade do sistema econômico expropriador para o comércio.

Ao observarmos o desenvolvimento de Blumenau nesse prisma, torna-se evidente que o papel central ocupado pela gestão colonial nos movimentos de apropriação centralizava-se na construção de vias de transporte para o escoamento dos produtos que chegavam e saiam de seu porto fluvial.

Enquanto a pequena propriedade referenciava o modelo de construção da subsistência, como a produção de alimentos, os denominados excedentes - que originariam os produtos realmente importantes para o fluxo comercial - estavam vinculados à produção das fazendas comerciais oriundas do sistema desigual de distribuição de terra. Ser um pequeno proprietário ou não ter propriedade significava ausência de autonomia, dada a baixa produtividade do lote, e a necessária venda de força de trabalho para as empresas comerciais dos maiores proprietários voltados à extração de madeira ou para as obras de infraestrutura financiadas pelo Estado brasileiro ou pelo investimento estrangeiro.

\footnotetext{
${ }^{2}$ It should be noted, however, that in the nineteenth century private hands were commonly associated with transactions, while public hands were usually credited with dispositions (Ibidem, p. 248.)

${ }^{3}$ Emphasis on "acquisition of goods from a distance" as constitutive element in trade should bring out de dominant role played by de import interest in the early history of trade. In the nineteenth century export interests loomed large - a typically catalectic phenomenon (Ibidem, p. 258).
} 


\section{Fazenda e mercado na colonização do Brasil meridional}

Indicando a indistinção entre as esferas política e econômica para o desenvolvimento institucional da economia de mercado do século XIX, necessitamos analisar o desenvolvimento dos meios de apropriação em paralelo com as instituições públicas e privadas que influenciaram os diferentes agentes envolvidos na colonização, unificando-os em torno da mesma matriz produtiva e delineando distintos papéis a apropriadores e produtores diretos (WOOD, 2003).

Ao observarmos o conjunto das análises histórico-econômicas relacionadas à constituição da economia colonial brasileira, encontraremos propostas institucionais que tratam de modo distinto a organização econômica e política do território, explicando a desigualdade econômica a partir de interpretações de caráter político, assentados principalmente em considerações relativas à desigualdade racial dos elementos componentes da população brasileira em desenvolvimento. A base destes modelos interpretativos parte das instituições europeias como autênticas catalisadoras do progresso capitalista sobre as nações coloniais. A "raça" branca estaria em vantagem devido ao seu papel fundacional sobre as instituições modernas de caráter capitalista, sendo os povos colonizados obrigados a apreender o sentido de suas instituições como meio para atingir alguma legitimidade.

Um exemplo dessa interpretação pode ser encontrado na obra "Populações Meridionais do Brasil", de Oliveira Vianna (2005), numa prática teórica que parte de um autoritarismo doutrinário, o reconhecimento do poder do apropriador é explicado pela sua condição étnica, o que transfere para a esfera cultural as razões de sua dominação econômica. Um campo econômico autônomo circunscreveria assim uma formação social autônoma, com relações internas próprias que explicariam suas desigualdades distributivas.

Para Oliveira Vianna (2005), o conjunto da população brasileira era apática, incapaz de formular os critérios civilizatórios próprios das luzes europeias. A filosofia da Revolução Francesa teria sido aqui assimilada pela intelectualidade branca, seus valores de liberdade, igualdade e fraternidade construídos diretamente em favor de uma política de construção progressiva do sistema de mercado. O mediador desse processo em relação ao restante do conjunto da população seria o progresso, materializado pelo aumento da oferta de bens e serviços aos espaços colonizados.

Em defesa desta noção de progresso, os custos de muitos investimentos coloniais foram relegados a análises amenas em relação às suas consequências totais para o ordenamento institucional das localidades afetadas por suas transações. Percebido desde a chegada de recursos e elementos materiais externos à colônia, o "progresso" facilitou o apoio do conjunto da população colonial em relação aos benefícios dos empreendimentos voltados à apropriação dos recursos do 
território, era também este comércio que propiciava o lucro dos empreendimentos, seja o latifúndio, conforme implementado por Portugal, ou, como veremos, as empresas comerciais, conforme operavam no contexto do Vale do Itajaí.

Estaria na cultura da Europa a base para a construção de uma nova sociabilidade no Brasil. Como referência para esta premissa, encontraremos em Oliveira Vianna (2005) a defesa frequente do modelo colonial de ocupação de pequenas propriedades por imigrantes de origem alemã no sul do Brasil. Particularmente em relação à suposta ausência de força de trabalho escrava e presença de um eficiente sistema de distribuição de lotes para configuração do regime produtivo, que induziria uma economia mais desenvolvida e uma cultura mais avançada, dado que seu povo não mais viveria nas condições servis impostas pelo latifúndio.

Oliveira Vianna (1974, 2005) traça suas definições antropológicas desde considerações comparativas com as sociedades europeias, situando-as como historicamente maduras e estáveis, fornecedoras de um quadro de referências ideal para a constituição dos Estados colonizados. A possibilidade de ordenamento econômico proviria da aproximação com estes costumes, tomados pelo autor para justificar a existência de suas concepções institucionais. E o valor fundamental transferido da Europa seria o trabalho, mas não o trabalho enquanto fenômeno social, mas como virtude inerente ao apropriador.

A situação específica da colonização brasileira e seu sentido comercial externo permitiam às classes dominantes organizar sua ação política desde o confronto entre os investimentos produtivos rentistas e a classe comercial financiadora destas atividades, deslocando o debate sobre o trabalho para um campo de relações supostamente internas a cada benfeitoria ou região, e organizados segundo ordenamentos institucionais orientados por critérios étnicos em detrimento das relações econômicas de apropriação.

Em relação ao Vale do Itajaí desde meados do século XIX, observamos que um pequeno grupo inicial de empreiteiros comerciais - favorecidos pelo acesso a investimentos externos, da Coroa Brasileira ou do comércio alemão, tornar-se-iam dominantes dos modos de apropriação do território. Destarte, a força de trabalho seria instituída por diferentes grupos culturais engajados nas novas relações de produção através da migração (MOREIRA, 1995; PIAZZA, 1975; KORMANN, 1994).

Os imigrantes pobres encontrariam na colônia e posterior município de Blumenau, além dos indígenas Xokleng - levados à condição de antagonistas pelo domínio do território (SANTOS, 1973) -, o afluxo de migração interna oriunda dos movimentos das populações luso-brasileiras, açorianas e africanas atraídas para a região desde o século XIX em virtude da ocupação inicial da foz do rio Itajaí. A força de trabalho que engendrou o domínio comercial da região foi, desde seu início, diversa em sua composição étnica. Mas o domínio dos comerciantes 
alemães sobre a colonização operada a partir da colônia Blumenau, aliada ao contexto histórico-político de legitimidade da dominação branca no contexto nacional, levaria à exclusão política tanto do negro e do indígena, quanto do próprio brasileiro pobre de origem migrante, na construção da história oficial do interior do Vale do Itajaí.

\section{Força de trabalho e mercado na colonização de Blumenau/SC}

A ascensão monopolista da produção cafeeira no Brasil do século XIX submeteu a maioria dos setores produtivos nacionais aos interesses do uso produtivo do território para a exportação primária do produto (PRADO JUNIOR, 1986). As iniciativas internas de empreendimentos produtores de mercadorias iriam explorar os recursos requisitados por esses grupos dominantes para a expansão de seu modo de apropriação. A receita externa obtida com o café formou a base para a produção dirigida ao consumo interno, sendo reforçada pela extensa abertura ao capital estrangeiro que ocorreria principalmente a partir do Segundo Reinado.

A região do Vale do Itajaí não estava isolada deste contexto interno, mas possuía relevância econômica secundária devido a seu baixo grau de ocupação e produção para o mercado no início do século XIX. Aos interessados no uso econômico destas terras de forma integrada à economia nacional, restava a exploração de atividades voltadas ao mercado interno - fundamentalmente constituído por Rio de Janeiro e São Paulo e as antigas províncias do nordeste como Bahia e Pernambuco (SILVA, 1954; SINGER, 1977; DEEKE, 1995; CEAG/SC, 1980; GOULARTI FILHO, 2007).

É com esse direcionamento que podemos localizar a fundação de Itajaí - na foz do rio Itajaí-Açú - na segunda década do século XIX. Atribuída a um comerciante de origem luso-brasileira, Agostinho Alves Ramos ${ }^{4}$, que teria sido o primeiro fazendeiro comercial a operar a exploração direcionada ao mercado dos recursos da região do Vale, ao fundar uma serraria às margens do Rio Itajaí e abrir o caminho para a formação de outras feitorias na região. A constituição dessas fazendas foi acompanhada pelo início do fluxo de migração interna de brasileiros e alemães - em sua maioria comerciantes e agricultores provenientes da colônia de São Pedro de Alcântara - que ocuparam gradativamente pequenas porções de terra na região, expandindo-se lentamente pelo interior do Vale (MOREIRA, 1995; SEYFERTH, 1999).

\footnotetext{
${ }^{4}$ A partir de 1823, como dono de importante casa de comércio, havia se tornado o chefe político da região. Elegeu-se deputado provincial e foi encarregado pelo governo para diversas missões, entre outras como diretor das colônias estabelecidas no interior do Vale do Itajaí (RICHTER, 2006, p. 31).
} 
A partir de 1850, a admissão da força de trabalho livre tornou necessária a reorganização das atividades produtivas brasileiras: a presença de trabalhadores livres iria gradativamente formar um mercado de consumo interno dirigido pelos comerciantes de exportação e importação que viabilizaram os meios necessários para a migração e fixação de imigrantes europeus em solo brasileiro. As ações de Agostinho Alves Ramos, no incentivo à colonização do interior do Vale do Itajaí, ocorreram justamente em favor dessa perspectiva de reorganização da produção local direcionada ao aumento do fluxo comercial. A ocupação do interior do Vale iria tanto alimentar o fluxo de força de trabalho necessário para a extração da madeira e a produção agropecuária, como gerar mercado consumidor para os produtos importados pelo porto ${ }^{5}$.

Inserido nesse contexto, é fundado em 1850 o estabelecimento comercial e colonial de Hermann Blumenau. Suas primeiras atividades econômicas foram direcionadas aos produtos que encontravam possibilidade de inserção no mercado nacional via Porto de Itajaí, sobretudo a madeira, comercializada, entre outros, por Alves Ramos ${ }^{6}$. Quando Blumenau chegou às terras adquiridas no interior do Vale e levantou sua serraria a partir de força de trabalho escravo, seu empreendimento era uma pequena empresa comercial indistinta das demais existentes perto da foz do rio Itajaí, com a diferença de que, a partir do início do povoamento por estrangeiros em 1852, o trabalho escravo teve que necessariamente ser extinto no território e entraria em cena o novo modo de expropriação da força de trabalho, que tornou superada a produção escravista na região: a articulação da pequena propriedade rural com as empresas comerciais de importação e exportação.

As características inerentes à formação institucional do empreendimento colonial de Blumenau possuem a singularidade inicial da presença de força de trabalho de origem europeia como catalisadora, via migração - o processo de migração de europeus é aqui defendido como uma importante base para o desenvolvimento do comércio transatlântico, na medida em que sua viagem além-mar constituía fonte de lucro aos operadores de transporte marítimo (COSTA LEITE, 1992; MEZZADRA, 2005). Mas a economia nacional, que condicionou $\mathrm{o}$ desenvolvimento desse novo modo de organização produtiva, forçou a competição interna com outros empreendimentos - ainda sustentados no modo

\footnotetext{
${ }^{5}$ Por essa razão, a expansão portuária e do próprio núcleo comercial (Itajaî) prende-se, desde cedo, à demanda das terras que margeiam os rios Itajaí-Açu e Mirim, acentuando-se essa expansão com a implantação das colônias Itajaí (Brusque) e Blumenau, entre 1850 e 1860. (MOREIRA, 1995, p. 82).

${ }^{6}$ Motivada pela presença do porto, a exportação da madeira nos decênios seguintes, irá comparecer como atividade básica em novas firmas comerciais instaladas no centro portuário, gerenciadas por imigrantes alemães como Malburg, Konder e Asseburg, entre outros, que irão projetar-se localmente como comerciantes-armadores, articulando, principalmente, o comércio portuário às boas oportunidades do "momento colonizador" (MOREIRA, 1995, p. 86).
} 
de produção escravista - que resistiu até praticamente a fundação da República. A solução adotada pelos comerciantes que atuaram na colonização de Blumenau, para competir com a situação escravocrata da economia nacional, foi construída desde a intensa exploração do trabalho desses novos imigrantes, no controle sobre a produção e comércio das mercadorias e no poder político sobre as instituições estatais.

Encontramos uma das mais expressivas visões materializadoras dessa perspectiva de construção cultural e política local na obra "Colonização e Indústria no Vale do Itajấ". Ao conduzir sua análise a partir de atribuição secundária aos recursos naturais presentes no Vale do Itajá, Renaux-Hering (1987) conduz uma teoria do desenvolvimento dos meios de apropriação organizados a partir da migração alemã como reconstrução cultural de uma tradição alicerçada na Europa, destituindo o papel chave que os atores e recursos econômicos já presentes na região - principalmente a madeira e a força de trabalho brasileira - tomaram durante a instituição econômica e política do Vale do Itajá́.

$\mathrm{O}$ fato da migração corresponder ao mecanismo mais importante de incremento de força de trabalho para o empreendimento colonial de Blumenau já torna impossível esta premissa isoladora, já que este ator concreto provinha de fora e realizava a primeira transação comercial com efeitos sobre o território. A migração estrangeira constituiu movimento de abertura da região ao mercado exterior, abertura que não poderia alcançar um novo isolamento.

Observamos que para Renaux-Hering (1987) o modelo do empreendedor individual - disposto à acumulação desde o princípio liberal do interesse - é o referencial para sua defesa do protagonismo do comerciante no processo de acumulação na colônia, as relações pessoais entre os agentes comerciais situados no Brasil e na Alemanha são tomados como "relações pessoais no intercâmbio", destituindo-os de qualquer papel nas ações econômicas impulsionadas localmente. $\mathrm{O}$ intercâmbio, no caso das economias coloniais, possui importância fundamental para a compreensão da organização produtiva, não podemos considerar suas relações como imbuídas apenas de um caráter pessoal (MARX, 2010; POLANYI; ARENSBERG; PEARSON, 1957).

Ao retirar de sua análise as relações comerciais e o papel das instituições governamentais na compreensão da acumulação local, resta à pesquisadora centralizar suas justificativas em torno de diferenciais qualitativos em termos de força de trabalho e empreendedorismo no Vale do Itajaí, levando a uma compreensão teleológica da história da cidade de Blumenau. Para explicar esse diferencial qualitativo, Renaux-Hering (1987) toma o processo de desenvolvimento da indústria têxtil como a referência chave, tratando de forma secundária o processo inicial de ocupação, qualificado como fase de subsistência e acumulação de poupança até que o "germe empreendedor" alcançasse clima propício para o amadurecimento. 
Ao situar os fatores externos ao mercado local como desnecessários à análise da formação econômica local, Renaux-Hering (1987) defende uma suposta harmonia de interesses entre a força de trabalho migrante e os comerciantes - migrantes mais antigos - que teria como resultado o desenvolvimento institucional autônomo de instâncias econômicas, numa possível analogia com o fazendeirocomerciante sugerido por Oliveira Vianna (2005), em que o poder político dos grupos estaria assentado num clã que manteria sua integridade cultural. A constituição desta narrativa histórica destaca os elementos da cultura alemã como catalisadores do progresso, gestando uma perspectiva discursiva de homogeneidade cultural com ênfase nas relações de fraternidade entre empreendedores e colonos.

Em nossa perspectiva, a história da colonização e desenvolvimento da região de Blumenau aparece orientada, desde seu início, pela constituição de uma organização produtiva assentada nas possibilidades de exploração dos recursos naturais para exportação e no domínio sobre as instituições políticas e produtivas do território. O papel dos agentes estatais no financiamento dos meios de distribuição da produção local a partir do repasse de recursos à gestão da colônia/cidade, bem como a injeção de capital estrangeiro a partir do final do século XIX são igualmente determinantes para a compreensão da acumulação originária local, precedendo assim o debate sobre a industrialização que ocorreria no século XX, e sendo fundamentais para uma compreensão mais abrangente daquele processo.

Em relação à problemática da colonização de Blumenau, percebemos que a defesa da tradição cultural germânica foi utilizada pelos agentes políticos e comerciais como recurso ideológico voltado a interesses econômicos mais que na manutenção da própria cultura do colono europeu. Ao contrário disso, a defesa política do imigrante muitas vezes ocorria ao mesmo tempo em que o poder de decisão acerca de sua própria subsistência estaria relacionado aos imperativos do capital comercial direcionado pelos investimentos dos grupos dominantes do mercado local e da gestão governamental.

A imagem idealizada de um trabalhador camponês, que produz sua subsistência e vende o excedente como meio de acesso a bens extras de origem externa à sua propriedade, não pode ser aplicada como determinante da acumulação originária do município de Blumenau, já que as pequenas propriedades se encontravam, desde o início de sua implementação, sob o jugo dos interesses comerciais dos agentes políticos dominantes dos meios de apropriação e produção de mercadorias. Também a industrialização não pode ser explicada a partir da poupança supostamente constituída da venda daquele excedente agrícola do colono, pois as mercadorias que de fato operaram a acumulação inicial de capital nas terras do Vale foram aquelas mais rentáveis e de valorização em curto prazo no mercado interno, dá a importância inicial da madeira como produto de valorização imediata no mercado do Rio de Janeiro do século XIX e XX, ela 
constituiu a base para a inserção do Vale do Itajaí no contexto da economia nacional, assim como só foi inserida neste mercado a partir da concessão das terras da foz do Itajaí-Açu a fazendeiros e comerciantes luso-brasileiros e alemães, abrindo o caminho para a expansão ao interior de uma economia colonial de base mercantil voltada ao comércio externo.

Onde o Governo não quis ou não pode oferecer o sacrifício necessário, a imigração se manteve baixa ou grandes capitais foram perdidos, deixando milhares de pessoas na miséria antes de preparar o caminho para o futuro das grandes levas migratórias. [...] O Governo brasileiro foi aconselhado e resolveu arcar com alguns sacrifícios, aplicando os recursos de modo benéfico, conforme mencionado, para ser mais fácil e seguro controlar e supervisionar os valores investidos (BLUMENAU, 2002, p. 65).

Sob a orientação liberal do Dr. Hermann Blumenau, estas instituições econômicas e políticas estavam organizadas de forma a construir relações estáveis de divisão das atividades produtivas. Este planejamento implicava a orientação direta da atividade do migrante interno e externo de acordo com suas possibilidades econômicas quando da chegada ao território. Quanto maior a quantidade de dinheiro trazido para investimento a longo prazo, melhor seria a situação social do recém-chegado, pelo menos até que se esgotassem as poupanças.

O modelo de gestão implementado na colônia Blumenau buscava criar redes de cooperação e competição econômica que permitissem o aproveitamento máximo da produtividade de trabalho do imigrante. Este direcionamento era garantido pela criação de redes de absorção da força de trabalho externa nos nichos já constituídos pelos comerciantes. Ao estabelecer-se na colônia, o imigrante assumia a tarefa de produzir renda para absorver novos produtos oriundos do comércio externo, atividade esta que seria sustentada pela exploração primária dos recursos da terra.

\section{Terra e lei}

O estabelecimento do modelo de produção baseado na pequena propriedade tem relevância fundamental para a análise da instituição econômica das colônias alemãs estabelecidas no Vale do Itajaí no século XIX. Sua emergência respondia às exigências de uma organização produtiva baseada no trabalho livre que se tornara irreversível no Brasil colonial. O modelo escravista, que dominava a produção econômica nacional, resistiu durante praticamente todo o século XIX (PRADO JUNIOR, 1986). Os grandes fazendeiros permaneceram renitentes ao estabelecimento de reformas, situação que faria com que os locais destinados à 
colonização por pequenas propriedades fossem escolhidos desde critérios não necessariamente vinculados a condições favoráveis de povoamento camponês estável, mas porque nestas regiões ainda não havia uma intervenção povoadora planejada ocasionando consequente baixa densidade demográfica.

O sistema de "colonização" terá mais sucesso no Extremo-Sul do país (Rio Grande, Santa Catarina, Paraná, e em maiores proporções no Espírito Santo, longe nestes casos da ação perturbadora e abrangente da grande lavoura. Encontrará aí o interesse e o estímulo dos governos locais das províncias, que procurarão solucionar com ele o problema de seus territórios quase desertos, e fomentar com o povoamento as atividades econômicas e as rendas públicas (PRADO JUNIOR, 1986, p. 189-190).

Ao chegar à colônia Blumenau, no Vale do Itajaí do século XIX, o imigrante pobre deveria trazer consigo: plenas condições de emprego de sua força de trabalho, capacidade para financiamento do lote de terra, uma boa ferramenta para a derrubada da madeira e, se possível, também uma arma (BLUMENAU, 2002). Essas recomendações demonstram uma série de contingências instituídas no território a ser colonizado agindo como orientadoras do padrão civilizatório local. Ao preparar o território para o uso produtivo da terra, empregar seu trabalho na construção das estradas e proteger sua propriedade com uma boa espingarda, o imigrante estaria sendo o pioneiro da instituição do Estado Nacional brasileiro sobre as terras consideradas primitivas.

O encontro entre índios e brancos no sul do Brasil, extensamente documentado na obra de Silvio Coelho dos Santos (1973), evidencia o processo de domínio e legitimidade institucional dos imigrantes, em detrimento aos indígenas Xokleng ${ }^{7}$, no processo de instituição da economia de mercado no Vale do Itajaí. O avanço da colonização, a partir de 1850, para o interior do Vale, determinou a dissolução das instituições indígenas no território. Essa dissolução seria financiada diretamente pelos imigrantes e executada em sua maioria por migrantes brasileiros, que teriam sido mobilizados pelos empreendedores coloniais para atuar em seu combate. Durante todo o século XIX, o conflito de brasileiros e estrangeiros contra o indígena originário seria financiado preponderantemente pelos envolvidos nos negócios da colonização e executado por tropas civis compostas

\footnotetext{
${ }^{7}$ Os índios Xokleng são conhecidos também pelas denominações Bugre, Botocudo, Aweikoma, Xokrén e Kaingang. O termo bugre é usado no sul do Brasil para designar indistintamente qualquer índio. Sua aplicação tem conotação pejorativa, pois encerra as noções de "selvagem" e "inimigo". (SANTOS, 1973, p. 30). Os Xokleng e Kaingang eram Jê, os célebres Tapuias, que desde logo os portugueses viram maiores dificuldades para submeter. (ibdem, p. 43). Uma designação posterior à obra de Silvio Coelho dos Santos, denominada "Laklanõ", isso é, "gente do sol" ou "gente ligeira" também pode ser encontrada na literatura sobre o tema.
} 
por nacionais (SANTOS, 1983). No século XX, com o advento da República, o Estado assumiria a responsabilidade pelo conflito, mas apenas para sagrar a vitória da propriedade privada e do mercado sobre o meio de vida dos indígenas originários.

O desenlace dessa trama institucional responsabilizaria os imigrantes alemães pela construção e legitimação das instituições modernizantes ordenadoras do modo de apropriação local. Embora a transferência dos valores culturais vinculados aos antigos modos de vida na Europa tenha sido consequência imediata da migração para a colônia/município, essa cultura seria organizada de acordo com os padrões necessários à produção voltada ao mercado, e atravessada por determinantes culturais locais, dos quais a relação com os indígenas constitui um exemplo. $\mathrm{O}$ processo de ocupação deixava o imigrante frente a frente com o indígena e legitimava o recém-chegado como autêntico conquistador da terra, tendo direito inclusive à dispensa militar a fim de permanecer no território (SANTOS, 1973).

Os pequenos proprietários e diaristas forneciam a força de trabalho para a constituição de uma economia favorável ao comerciante como meio para seu próprio desenvolvimento, alcançando legitimidade jurídica no território; os migrantes de origem brasileira, que também ocupariam o território no século XIX, não seriam incluídos como segmento estável da população local; os indígenas Xokleng, por não aceitarem o domínio do modelo privado de ocupação, só seriam incluídos na organização econômica após sua quase extinção e o estabelecimento de uma pequena área para os sobreviventes, onde, por força, acabaram por adaptar-se ao modo de vida baseado na propriedade e na extração de seus recursos (SANTOS, 1973).

Esta digressão histórica evidencia a relação entre as instituições econômicas voltadas ao mercado - na base da propriedade privada da terra - e a legitimidade atribuída ao imigrante como portador da cultura da qual teriam se originado estas instituições. Para os negócios da migração essa vinculação seria fundamental, posto que o imigrante desejava encontrar condições seguras de existência no novo território. Tal fato levou muitos defensores da colonização a omitir deliberadamente dados sobre a presença indígena no interior do Vale, ou mesmo a presença de negros e caboclos.

O desenvolvimento dos meios de apropriação no território colonizado no Vale do Itajaí, desde meados do século XIX, teve como pressuposto normativo para a organização social da exploração a distribuição de lotes de terra para a pequena propriedade fundiária. Esta pequena propriedade, contudo, já nascia como derivação da concessão inicial de terras obtida pelo Dr. Hermann Blumenau, que definiam o empreendimento colonial inicial como uma característica empresa comercial baseada na exploração dos recursos da terra através do emprego de força de trabalho estrangeira. 
Essa subsunção formal da pequena propriedade ao mercado, já no início do empreendimento comercial, evidencia que a migração e a apropriação comercial do território estavam relacionadas de forma a construir um modelo de povoamento organizado, que definia a inclusão social do migrante interno ou externo a partir de suas possibilidades financeiras quando da chegada na colônia/município de Blumenau. Esse processo desencadeou uma série de relações que utilizaram o lobby como meio de organização da força de trabalho disponível para os empreendimentos.

Embora desde 1870 a diversidade do conjunto étnico envolvido na trama da colonização não permitisse uma visão homogênea acerca de suas origens culturais (SEYFERTH, 1999), seu avanço instituiu relações econômicas que romperam o distanciamento entre os grupos localizados no território. $\mathrm{O}$ acesso à propriedade $\mathrm{e}$ aos recursos foi a chave para estas relações, culminando no fim do século XIX com uma organização estratificada a partir do poder político do apropriador e da segregação dos grupos pobres de acordo com seu papel na economia instituída. A descrição de Silvio Coelho do Santos sobre a construção das relações de classe na região de Ibirama - no Alto Vale do Itajaí - no início do século XX pode ser identificada como o resultado da organização econômica voltada ao comércio externo que tomaria o território do Vale no século XIX.

A interdependência de interesses entre a agricultura e a atividade madeireira, juntamente com a detenção de maior ou menor quantidade de terras, fundamentou a estratificação social da área. $\mathrm{Na}$ base da pirâmide estão localizados colonos e caboclos brasileiros, nãoproprietários, que sobrevivem pela venda de sua força de trabalho. À parte desses, e abaixo, situam-se os indígenas e os mestiços que residem na reserva. Acima, em direção do vértice, em estratos diferentes, situam-se desde os pequenos proprietários até os detentores de largas extensões de terra e proprietários de empresas madeireiras (SANTOS, 1973, p. 247).

O processo histórico de conquista do Vale do Itajaí, nesse aspecto, corresponde à expulsão sistemática dos habitantes originários para as regiões ao interior do Vale e sua substituição por imigrantes assentados em pequenas propriedades. A ausência de legitimidade do indígena permitia ao colono o uso deliberado da violência, sem que a isso estivesse implicado algum risco mediante a comunidade. "O matador de bugres era heroicamente solicitado a contar suas façanhas. Nas reuniões da parentela, nas rodas que se formavam durante as festas de igreja, nas bodegas, os casos que envolviam indígenas e seus caçadores sempre atraíam ouvintes durante horas seguidas." (SANTOS, 1973, p. 87).

Esse processo de acumulação - orientado pela exploração primária da terra e pela migração - oferecia alguns caminhos para o imigrante europeu sem recursos que 
chegava à região de Blumenau: (1) venda de força de trabalho nas obras estruturais geridas pela direção da colônia/município e coordenadas pelas empresas comerciais, o que o instituía na condição de realizador do capital oriundo dos empréstimos do Império brasileiro; (2) venda de força de trabalho para a transformação dos recursos naturais da colônia em mercadorias comercializáveis, com destaque para a madeira, prática inicialmente operada de forma dispersa pelos primeiros habitantes no século XIX e, progressivamente, monopolizada pelas empresas comerciais. A realização da venda do produto possibilitava a importação dos gêneros não produzidos localmente que eram distribuídos pelos mesmos comerciantes que operavam as atividades extrativas, o que gerava dependência entre o colono e o comerciante; (3) Como produtor de mercadorias comercializáveis a partir da produção agropecuária na pequena propriedade, embora seja a alternativa que estabelecia maior autonomia ao produtor, esta autonomia também estava condicionada à oferta de produtos que possuíssem demanda fora da colônia/município, ou seja, demandas comerciais externas. Essa trama produtivo-exploratória configurou os determinantes da construção da existência dos colonos trabalhadores.

Sobre esta base inicial construíram-se as relações de apropriação locais do vale do Itajaí. No decurso histórico desse processo, o maior ou menor fluxo de investimentos na colônia estava condicionado aos investimentos auferidos junto ao governo federal e ao fluxo migratório como atividade comercial. Até o fim do século XIX, nas condições imperiais brasileiras, não foram criadas disposições para investimentos de maior alcance capazes de alterar de forma revolucionária as condições de produção locais. Este feito só seria alcançado no período republicano, mas estaria assentado nos mesmos princípios organizadores já presentes na gênese da Colônia Blumenau: a centralização comercial das atividades de produção e distribuição de mercadorias e o atrelamento dos interesses públicos da gestão municipal à construção de infraestrutura em favor das empresas comerciais que operavam os negócios de importação e exportação. Em suma, o desenvolvimento da cidade não estava voltado a interesses de constituição de uma sociedade democrática e culturalmente desenvolvida, em algum sentido planejado, mas à viabilização contínua dos investimentos comerciais.

Desta tomada das definições de costume pelo direito, como meio de institucionalização da propriedade privada, podemos verificar a base políticoeconômica que sustentou a defesa da cultura germânica como autêntica conquistadora das terras do Vale do Itajaí: as bases políticas da dominação comercial seriam legitimadas pela suposta tradição agrária dos imigrantes pobres, em oposição à suposta vocação comercial dos fazendeiros comerciais dominantes. Os costumes germânicos foram interpretados em favor do ordenamento institucional liberal do empreendimento, ou seja, na perspectiva dos novos dominantes, encobrindo a diversidade étnica presente nos grupos trabalhadores 
que não possuíam protagonismo político reconhecido na instituição da economia regional.

\section{Considerações finais}

A colonização alemã em escala significativa no sul do Brasil constitui um fenômeno recente da história brasileira, decorrente também da entrada tardia da Alemanha no marco imperialista dos séculos XIX e início do XX. O sistema de economia de mercado cresceria de forma acelerada levando as economias europeias à expansão do comércio exterior voltado aos negócios coloniais. Em virtude desse processo, os negócios de importação e exportação tornaram-se mediadores diretos da construção das instituições políticas e econômicas da colônia e do município de Blumenau.

O encadeamento das relações entre os movimentos de apropriação da riqueza local - como a extração de madeira, que já era atividade econômica em evidência na região de Itajaí no início do século XIX - e os empreendimentos comerciais alemães, ocorreram com a mediação direta da migração para fins colonizadores. Foi com o início das operações de transporte de emigrantes para o Vale do Itajaí que vislumbramos o início da inserção desta região no contexto da economia de mercado em franca expansão no século XIX.

Embora o regime de pequena propriedade definisse as condições jurídicas de acesso à colônia, o vetor da continuidade do fluxo de trocas que manteria as instituições coloniais dependia diretamente das fazendas comerciais, resultantes do crescimento de um grupo que, desde os primórdios da colônia, centralizaria a definição das disposições institucionais locais.

O arranjo distributivo das terras correspondia antes à necessidade do domínio do território e da abertura de caminhos que ao desenvolvimento específico de um modelo de povoamento. As condições para a inserção efetiva na economia de mercado já estavam dadas desde a fundação: a capacidade de extração dos produtos da terra e sua inserção como mercadoria nas redes de comércio, retroalimentadas pelo aumento da força de trabalho pela migração.

As relações entre os comerciantes locais do Vale do Itajaí, e destes com a República brasileira e os comerciantes hamburgueses, passaram por distintos momentos e características ao longo do processo. A integração com a economia da Alemanha alcançaria seu momento de maior ânimo com a implantação das colônias da Companhia Colonizadora Hanseática e com a construção da ferrovia EFSC (Estrada de Ferro Santa Catarina). Mas, ao mesmo tempo, cresceria a dependência em relação às metrópoles do sudeste brasileiro. 
A historiografia indica que em todas as levas migratórias operadas pelo Dr. Hermann Blumenau o índice de rejeição à Colônia, após a chegada, fora alarmante. Seus textos de recomendação, escritos já na fundação, tornavam clara esta preocupação com o possível fracasso da empreitada colonizadora. Em virtude das limitações produtivas deste contexto de economia embrionária, a transformação da cidade de Blumenau como polo significativo para a economia de Santa Catarina só viria a acontecer após a proclamação da República e a queda da Revolução Federalista, quando o aumento dos investimentos externos impulsionados pela Companhia Colonizadora Hanseática - iria alterar as condições de produção e apropriação da economia local.

O fluxo migratório interno e externo alcançou a possibilidade de mudar a quantidade e a qualidade da força de trabalho de forma mais rápida que pelo simples crescimento demográfico. Esta força de trabalho aceleraria o aumento da produtividade nos períodos em que o capital comercial encontrava possibilidades externas de mediação para o crescimento. A colonização alcançaria seu progresso a partir dos impulsos mais ou menos intensivos do processo migratório em relação à entrada de capital institucionalizado para os negócios da cidade.

No período de transição republicana de fins do século XIX e início do XX, o governo federal agiria como propulsor de investimentos nos centros econômicos do interior do Brasil, utilizando a capacidade de investimento e consumo das economias do Sudeste para envolver o restante do país num sistema minimamente integrado. Paralelamente, iria expandir e fragmentar a capitalização estrangeira para sanar suas dificuldades de equilíbrio financeiro no mercado mundial. No fim desse período, observaremos a aceleração do movimento de urbanização da cidade de Blumenau desde a migração interna oriunda do campo. Esse processo ocorreria em paralelo à continuidade do assentamento de estrangeiros e de teuto-brasileiros no interior da região, num fenômeno que gradativamente formaria as bases para relativa segregação entre os trabalhadores urbanos e o setor camponês, que também sofreria os impactos da injeção de capital na colônia a partir da centralização cada vez maior do poder distributivo dos comerciantes.

\section{Referências}

BLumenau, H. B. O. A colônia alemã Blumenau na Província de Santa Catarina no sul do Brasil. Blumenau: Cultura em Movimento - Instituto Blumenau 150 Anos, 2002.

CEAG/SC. Evolução histórico-econômica de Santa Catarina: estudo das alterações estruturais (século XVII-1960). Florianópolis: CEAG/SC, 1980. 
COSTA LEITE, J. Os Negócios da emigração (1870 -1914). Análise Social, v. XXXI n. 136/137, 1992.

DEEKE, J. O Município de Blumenau e a história de seu desenvolvimento. Blumenau: Nova Letra, 1995.

FERNANDES, F. Fundamentos empíricos da explicação sociológica. São Paulo: Companhia Editora Nacional, 1959.

Sociedade de classe e subdesenvolvimento. Rio de Janeiro: Zahar Editores, 1972.

A Revolução Burguesa no Brasil. Rio de Janeiro: Zahar Editores, 1976.

GOULARTI FILHO, A. A Formação econômica de Santa Catarina. Florianópolis: Ed. da UFSC, 2007.

KORMANN, E. Blumenau - arte, cultura e as histórias de sua gente (1850 1985). Florianópolis: Paralelo 27, 1994. (Volumes I, II e III).

LANDER, E. A colonialidade do saber: eurocentrismo e ciências sociais. Perspectivas latinoamericanas. Buenos Aires: CLACSO, Colección Sur Sur, 2005.

MARX, K. O Capital - Crítica da Economia Política. Livro 1: O Processo de produção do Capital. Volume II, $4^{a}$ edição. Rio de Janeiro: Bertrand Brasil, 1989.

O Capital - Crítica da Economia Política. Livro 3: O Processo Global de

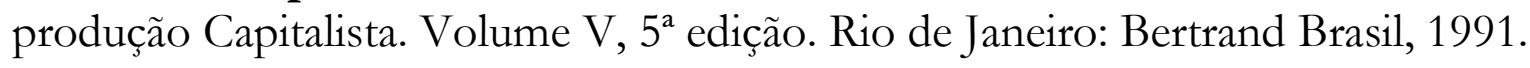

A ideologia alemã. Rio de Janeiro: Civilização Brasileira, 2007.

O Capital: crítica da economia política. Rio de Janeiro: Civilização Brasileira, 2010.

- Grundrisse: manuscritos econômicos de 1857-1858: esboços da crítica da economia política. São Paulo: Boitempo; Rio de Janeiro: Ed. UFRJ, 2011.

MEZZADRA, S. Derecho de fuga: migraciones, ciudadania y globalización. Madrid: Traficantes de sueños, 2005. 
MOREIRA, S. M. T. Porto de Itajaí: da gênese aos dias atuais. Dissertação de mestrado em Geografia. Universidade Federal de Santa Catarina: Florianópolis, 1995.

PIAZZA, W. F. A "modernização" e as elites emergentes: a contribuição alemã. Revista Blumenau em Cadernos, Blumenau, n. 7, jul. 1975.

POLANYI, K. A Grande Transformação: as origens da nossa época. 2. ed. Rio de Janeiro: Campus, 2000.

POLANYI, K.; ARENSBERG, C. M.; PEARSON, H. W. Trade and market in the early empires: economies in history and theory. New York: The Free Press. London: Collier-Macmillan, 1957.

PRADO JUNIOR, C. Formação do Brasil contemporâneo: colônia. 6 ed. S. Paulo: Brasiliense, 1961.

História econômica do Brasil. 34 ed. São Paulo: Brasiliense, 1986.

RENAUX-HERING, M. L. Colonização e indústria no Vale do Itajaí: o modelo catarinense de desenvolvimento. Blumenau: Editora da FURB, 1987.

RICHTER, K. A sociedade colonizadora hanseática de 1897 e a colonização do interior de Joinville e Blumenau. Blumenau: FURB, 1992.

. Primórdios da colonização sistemática em Santa Catarina - 1846-1848. Revista do Instituto Geográfico de Santa Catarina, Florianópolis n. 23, 2004.

. As raízes de Blumenau: 1847 - 1850. Revista Blumenau em Cadernos. Blumenau, Tomo XLVII - n. 01/02, 2006.

A primeira viagem do Dr. Blumenau para Santa Catarina em abril de 1847. Revista Blumenau em Cadernos, Blumenau, Tomo XLVIII, n. 11/12, 2007.

SANTOS, S. C. Índios e Brancos no sul do Brasil: a dramática experiência dos Xokleng. Florianópolis: Edeme, 1973.

SEYFERTH, G. Etnicidade, política e ascensão social: um exemplo teutobrasileiro. Maná, Rio de Janeiro, v. 5, n. 2, Out., 1999. 
SINGER, P. I. Desenvolvimento econômico e evolução urbana: análise da evolução econômica de São Paulo, Blumenau, Porto Alegre, Belo Horizonte e Recife. 2 ed. São Paulo: Editora Nacional, 1977.

SILVA, Z. P. O Vale do Itajaí. Rio de Janeiro: Ministério da Agricultura, 1954.

VIANNA, O. Problemas de Política Objetiva. 3 ed., Rio de Janeiro: Record, 1974.

. Populações Meridionais do Brasil. Brasília, Senado Federal: Conselho Editorial, 2005.

WOOD, E. M. Democracia contra capitalismo: a renovação do materialismo histórico. São Paulo: Boitempo, 2003.

Endereço para correspondência:

Cleiton Junior Pereira da Rocha - cleitonrochajr@gmail.com

Rua Antônio da Veiga, 140, Campus 1, Sala J-003

89012-900 Blumenau/SC, Brasil 